\title{
El reto de imaginar ciudadanías plenas
}

\section{The challenge of imagining integral citizenships}

\author{
Jorge Luis Yangali Vargas 1,a \\ https://orcid.org/0000-0003-3714-326X
}

Recibido: 30-10-2020

Aceptado: 17-11-2020

\section{Citar como}

YangaliVargas,J. (2020). Elreto deimaginarciudadanías plenas. Desafíos. 2020; 11(2):119-20.https://doi.org/10.37711/desafios.2020.11.2.206

A puertas del bicentenario, el Consejo Nacional de Educación del Perú publicó el Proyecto Educativo Nacional (2020) (o PEN 2036); una propuesta de largo aliento, como su antecesor, el PEN del 2006, pues su horizonte es el 2036 y cuyo principal derrotero es la formación de ciudadanos plenos. En razón del contexto, corrupción estructural y precariedad institucional que cada nueva generación hereda de la otra (García, 2016; Quiroz, 2013), la clase gobernante - entiéndase como los funcionarios del Ministerio de Educación y los mismos integrantes del Consejo Nacional de Educación (CNE) - propone, a la sociedad peruana, en general, y a los educadores, en particular, hacer un esfuerzo conjunto para lograr una ciudadanía plena.

Los autores del PEN 2036 entienden la ciudadanía como el ejercicio de los derechos, por parte de todas las personas. Cobertura que, en razón de la procedencia y origen de los ciudadanos que habitan el territorio peruano -muchos no nacidos en ella; por ejemplo, los inmigrantes venezolanos, muchos de los cuales vieron reducidos sus derechos elementales en la salud y educación y las enormes brechas socioeconómicas y de capital simbólico entre los peruanos, exigen del proyecto una realización urgente. El 2006, la misma institución, el CNE, pero con diferentes autores propuso una visión hacia el bicentenario en la que "todos (...) se asumen ciudadanos con derechos y responsabilidades" (p. 5); una visión que hasta hace poco se creía fallida (Constantino, 2012). No obstante, la participación masiva de los jóvenes, en estos meses finales del 2020, logrando derrocar un gobierno de facto con sus marchas de protesta, nos retornan la esperanza para seguir concibiendo las aulas escolares como cuna de una ciudadanía en la que prevalecen los criterios de justicia.

Imaginar ciudadanías, parafraseando las, "Comunidades imaginadas" de Anderson (1983), en las que los integrantes de las sociedades se identifiquen con los proyectos que sus gobernantes proponen no es una tarea de fácil construcción para los proyectistas ni de fácil identificación para los ejecutores. En una nación como la peruana, en la que se insiste en un planeamiento cuyo lugar de enunciación sigue siendo el centro, la realización del proyecto se complejiza muchísimo. Si bien, si la construcción del PEN 2036 siguió la metodología que toda formulación de políticas exige, como la evaluación del PEN anterior, la realización de espacios de diálogo y consulta, etc., este sigue incurriendo en presentarse como una propuesta centralista.

Un componente central de todo proyecto educativo tiene que ver con la solidez conceptual y, en consecuencia, con la revisión de la literatura pertinente. En el PEN 2036 se detalla que en su construcción se empleó "Io mejor del saber especializado sobre el tema educativo" (p. 16); aunque se desestimen propuestas educativas desde enfoques teóricos como el decolonial (Yangali 2017), la interculturalidad o la hospitalaria (Bárcena y Mèlich, 2000). Para aproximarnos a este "mejor" saber sobre el elemento eje del proyecto, la ciudadanía plena, es importante analizar críticamente la bibliografía empleada. Si exceptuamos los textos de las editoriales extranjeras, así como los documentos institucionales que tienen que referenciarse obligatoriamente como los del Ministerio de Educación o del Instituto Nacional de Estadística (INEI) u otras dependencias, este "mejor" saber sigue siendo producido en Lima y en contadas instituciones. No se lista ningún texto de autoría regional. En otras palabras, se le sigue diciendo a los peruanos que la única y válida 
ciudad letrada sigue siendo la capital peruana; por consiguiente, que la "mejor" ciudadanía peruana habita la Ciudad de los Reyes, a la que hay que imitar. Si radicalizáramos el análisis, observamos que las agencias del conocimiento educativo se adscriben, explícitamente en la bibliografía, a entidades de régimen privado; lo que transforma en paradoja y realidad abyecta la propuesta del PEN: un bien público y común o un derecho público de "†odo" ciudadano peruano, como lo es la educación, se tiene que imaginar a partir de insumos provistos por instituciones privadas.

Este breve análisis de la bibliografía del PEN 2036 nos retornan a una reflexión en la que venimos insistiendo años atrás (Yangali 2014; 2017), y que, en palabras de Russo y Klein, no hacen otra cosa que visibilizar la convivencia de subciudadanías. Por lo tanto, el reto para los autores del futuro PEN, aunque lo pertinente sería que los actuales lo rectifiquen, implica concebir un proyecto que no siga privilegiando una sola ciudadanía, un único y colonial lugar de enunciación del saber; sino que sea capaz de encontrar puntos, no importa si mínimos (Adorno, 2001), de convergencia entre estas subciudadanías peruanas y otras plenas, deseablemente universales.

\section{REFERENCIAS BIBLIOGRÁFICAS}

Adorno, T. (2001). Mínima moralia. Reflexiones desde la vida dañada (3.a ed.). Taurus.

Anderson, B. (1983). Comunidades Imaginadas. Fondo de Cultura Económica.

Bárcena, F. y Mèlich, J.C. (2000). La educación como acontecimiento ético. Paidós.

Consejo Nacional de Educación. (2006). Proyecto Educativo Nacional al 2021. http://www.minedu.gob.pe/Delnteres/xtras/PEN-2021.pdf
Consejo Nacional de Educación. (2020). Proyecto Educativo Nacional al 2036: el reto de la ciudadanía plena. http://www.cne.gob.pe/uploads/publicaciones/2020/ proyecto-educativo-nacional-al-2036.pdf

Constantino, R. (2012). Enseñando democracia: normativa, realidad y propuestas en torno a la educación para la ciudadanía en el Perú. Derecho PUCP, (68), 585-610. http://revistas.pucp.edu.pe/index.php/ derechopucp/article/view/2849

García Belaunde, V. A. (2016). El expediente Prado. Asociación Civil Mercurio Peruano.

Hernández-Vásquez, A., Vargas-Fernández, R., Rojas- Roque, C. y Bendezu-Quispe, G. (2019). Factores asociados a la no utilización de servicios de salud en inmigrantes venezolanos en Perú. Revista Peruana de Medicina Experimental y Salud Pública 36 (4), 583591. https://doi.org/10.17843/rpmesp.2019.360.4654

Quiroz, A. (2013). Historia de la corrupción en el Perú. Instituto de Estudios Peruanos e Instituto de Defensa Legal.

Russo, J. y Klein, A. (2020). La tercera edad en Latinoamérica y México. Un largo transitar entre la ciudadanía y las subciudadanías. Revista FORUM. Revista Departamento Ciencia Política, 18, 145-165. https://doi. org/10.15446/frdcp.n18.79546

Yangali Vargas, J.L. (2017). Derroteros de la educación peruana en el XXI: interculturalizar, decolonizar y subvertir. Ensaio: aval.pol.públ.Educ., 25(97), 918-942. https:// doi.org/10.1590/s0104-40362017002500988

Yangali Vargas, J. L. (2014) En la versión los senderos se sub( ) versan. EnJ.L. Yangali Vargas. Poesía y escena peruana contemporánea: Flor de María Ayala y María Teresa Zuñiga: o la sub-versión en tiempos de subversión. (pp. 12-84). Universidad Iberoamericana.

Correspondencia

Email: jyangali@uncp.edu.pe 